\title{
Overgrowth-a clinical review not only for geneticists
}

\author{
Dorothea Wand ${ }^{1}$
}

Received: 2 October 2019 / Accepted: 15 October 2019 / Published online: 28 October 2019

(c) European Society of Human Genetics 2019

Book: Overgrowth Syndromes - A clinical guide

Edited by: Giovanni Neri, Luigi Boccuto, Roger E. Stevenson

ISBN: 978-0-1909-4489-6

Published by: Oxford University Press 2019

Price: $£ 65.00$ / $\$ 99.95$ (hardcopy) also available as e-book

The Clinical Guide of Overgrowth Syndromes represents the heterogeneous group of rare diseases with manifestations that often overlap each other, requiring the use of preestablished diagnostic criteria in most cases. The clinical guide is an up-to-date compilation of the state of knowledge of overgrowth syndromes for which there is no alternative source in this compact form on 270 pages. The clearly structured design of the individual chapters facilitates access and a quick overview of the specific entities, Beckwith- Wiedemann-, Sotos-, Weaver- and EZH2-related overgrowth syndromes, Perlmann-, Malan-, PTEN-related overgrowth, Proteus syndromes, hemihypertrophy and hemihyperplasia, PIK3CA-related overgrowth spectrum, and vascular anomalies and their differential diagnoses. Each article provides a comprehensive overview of the selected topic.

In addition to the detailed clinical aspects, supported by a multitude of figures, tables and illustrations, diagnostic criteria, risks of neoplasia, molecular findings, pathogenic mechanism, inheritance, recurrence risk, treatment, and management are described comprehensively. A color design of the drawings, pictures, and graphics would have contributed to an optimal understanding of the details of specific aspects. Numerous bibliographical references that appear at the end of each chapter allow the possibility of an in-depth study of individual topics.

In addition, this book provides a well-founded and comprehensive overview of the latest scientific findings on overgrowth syndrome. It is a valuable, concise reference work for all those working in clinics and practices in the diagnosis, treatment, and management of patients with overgrowth syndromes and genetic family counseling.

Thanks to the authors and guest authors for this systematic and comprehensive Clinical Guide of Overgrowth Syndromes 17 years after the publication of Overgrowth Syndromes by Cohen, Neri, and Weksberg.

\section{Compliance with ethical standards}

Conflict of interest The author declares that she has no conflict of interest.

Publisher's note Springer Nature remains neutral with regard to jurisdictional claims in published maps and institutional affiliations.
Dorothea Wand

dorothea.wand@usb.ch

1 Department of Medical Genetic and Pathology, University Hospital of Basel, Basel, Switzerland 